\title{
An Investigation into the Thermal Properties of Termite Mound Clay Applicable to Grain Silo Construction
}

\author{
Omobowale Mobolaji Oluyimika*, Mijinyawa Yahaya, Faruk S. \\ Department of Agricultural and Environmental Engineering, University of Ibadan, Oyo State, Nigeria
}

\section{Email address:}

mo.omobowale@mail.ui.edu.ng (M. Omobowale)

\section{To cite this article:}

Omobowale Mobolaji Oluyimika, Mijinyawa Yahaya, Faruk S.. An Investigation into the Thermal Properties of Termite Mound Clay Applicable to Grain Silo Construction. International Journal of Materials Science and Applications. Vol. 4, No. 4, 2015 , pp. $266-271$. doi: $10.11648 /$ j.ijmsa.20150404.17

\begin{abstract}
Provision of suitable grain silos in humid tropical climates has generated research interests on the possibility of using local materials for construction. Termite mound clay (TMC), a material available in abundance was investigated as a potential construction material. A major factor determining the suitability of construction materials for grain silos is its thermal properties. Therefore, thermal conductivity, specific heat capacity, thermal diffusivity and thermal mass of TMC were determined and compared with those of concrete and stainless steel which are commonly used for silo construction. TMC was collected, crushed and sieved using a $500 \mu \mathrm{m}$ sieve to remove coarse particles and foreign materials. The TMC powder obtained was mixed with water using volumetric ratio of 1:5 (i.e. water to clay) after which the thoroughly mixed clay was carefully fed into the mould and left to air-dry for 5 days. The samples were dried in the oven at $105^{\circ} \mathrm{C}$ for about 48 hours to remove all the moisture. Results revealed that thermal conductivity ranged from 0.17 to $0.24 \mathrm{~W} /(\mathrm{m} \cdot \mathrm{K})$ with an average value of 0.21 compared to concrete and steel which range between $0.8-1.28$ and $16.3-16.7 \mathrm{~W} /(\mathrm{m} \cdot \mathrm{K})$ respectively. Specific heat capacity had an average value of $2576.94 \mathrm{~J} /(\mathrm{kg} \cdot \mathrm{K})$ compared with concrete and steel which had values of $960 \mathrm{and} 490 \mathrm{~J} /(\mathrm{kg} \cdot \mathrm{K})$ respectively. Thermal diffusivity had a mean value of $1.47 \times 10^{-8} \mathrm{~m}^{2} / \mathrm{s}$ in comparison to concrete and steel whose calculated values were $6.63 \times 10^{-7}$ and $4.18 \times 10^{-6} \mathrm{~kJ} /\left(\mathrm{m}^{3} \cdot \mathrm{K}\right)$ respectively while thermal mass had a mean value of $4723.5 \mathrm{~kJ} /\left(\mathrm{m}^{3} \cdot \mathrm{K}\right)$ compared to 2112.0 and $3831.8 \mathrm{~kJ} /\left(\mathrm{m}^{3} \cdot \mathrm{K}\right)$ for concrete and steel respectively. It was concluded that TMC offers a thermally suitable alternative to these two for grain silo construction in the humid tropics.
\end{abstract}

Keywords: Termite Mound Clay, Silo, Thermal Conductivity, Specific Heat Capacity, Thermal Diffusivity, Thermal Mass

\section{Introduction}

A crop storage structure refers to a container which is originally designed and fabricated or an existing structure that is remodeled for the primary purpose of safe keeping of crops from the harsh conditions of the ambient environment [1]. Throughout the storage period, a good storage structure is expected to protect stored produce and maintain their initial quality and enhance easy monitoring $[1,2]$.

Even though several materials have been used in the construction of storage structures among which are steel, concrete, wood, and plastic; these are faced with certain limitations which hampered its widespread use for on-farm storage in the tropical regions in sub-Saharan Africa. For instance, steel and concrete even though strong, are very expensive while wood is easily bio-degradable. Moreover, the problem of moisture condensation in steel and plastic silos has been widely reported [3].

Temperature is a major factor considered in the safe storage of grains. When an appreciable temperature gradient exists within bulk grains, it causes mold growth due to moisture migration [4]. A major factor influencing crop deterioration during storage is temperature because grains are biologically active, giving off heat during respiration [5]. In essence, any action taken to ensure a cool internal environment within storage structures like silos tends to reduce the rate of respiration thereby increasing the storage life by lessening the possibility of germination. It also decreases the metabolic rates of insects and fungi [5]. Moreover, at lower temperatures and moisture content, the growth of fungus, insect and mites is reduced [6].

Silos remain the most suitable structure for bulk grain 
storage and their performance is greatly influenced by the engineering properties of the construction material and the climatic environment where they are used [3, 7]. Some of the relevant thermal properties of materials suitable for silo construction include:

a Thermal conductivity: The ability of a material to conduct heat is a measure of its thermal conductivity usually expressed as the rate of heat transfer through a unit thickness of the material per unit area per unit temperature difference $(\mathrm{W} /(\mathrm{mK}))$. Low values indicate that the material is a poor conductor of heat [8]. Low thermal conductivity is desirable to ensure that total heat transmission into stored produce is limited most especially in the humid tropics. It varies with density, moisture content, ambient temperature, direction of heat flow, homogeneity of the material and porosity [9].

b Specific Heat Capacity: This is the amount of heat required to raise the temperature of a unit mass of a substance or material by a unit temperature and the S.I unit is joule per kilogram kelvin $\mathrm{J} /(\mathrm{kg} \cdot \mathrm{K})$. Specific heat capacity is one of the important parameters for determining the insulation property of a material [9]. Substances with high specific heat capacity absorb more energy before they change in temperature [10]. Such materials with high specific heat capacity are desirable for grain silo construction in tropical regions.

c Thermal diffusivity: Thermal diffusivity usually denoted as $(\alpha)$ is among the thermal properties of a material, which express the speed of change in temperature of a medium when exposed to changes in the thermal environment. It is a measure of the rate at which heat at one point in a material travels to another point by diffusion. It also indicates how fast a material will change its temperature. The thermal diffusivity is inversely proportional to the heat capacity and directly proportional to the thermal conductivity. It is expressed in $\mathrm{m}^{2} \mathrm{~s}^{-1}[9,11]$. Materials with high thermal diffusivity adjust rapidly to ambient temperature because heat is quickly conducted [10].

$\mathrm{d}$ Thermal mass: This is the heat storage capacity of a material and it is a function of its specific heat $\left(\mathrm{kJkg}^{-}\right.$ ${ }^{1} \mathrm{~K}$ ) and density [12]. Materials such as concrete, brick and stone used in building construction are known to store and release large quantities of thermal energy [13].

The need for the use of materials that will eliminate the problem of moisture condensation, durable, easy to work with, cheap and readily available to farmers, for the construction of silos was pointed out by [3]. They suggested Termite Mound Clay (TMC) as a suitable material of construction. Some mechanical properties of TMC were studied while recommending studies into its thermal properties. This study therefore investigated some of the thermal properties of TMC with particular reference to its suitability for use in grain silo construction.

\section{Methodology}

\subsection{Sample Collection and Preparation}

TMC was collected from Ogunranti village, Lagelu Local Government area of Oyo State (Figure 1), Nigeria after which they were ground and sieved using a $500 \mu \mathrm{m}$ sieve to remove coarse particles and foreign materials (Figure 2). The TMC powder obtained was mixed with water using volumetric ratio of 1:5 (i.e. water to clay). After thorough mixing, the clay was carefully fed into the mould and left to air-dry for 5 days after which the samples were dried in the oven at $105^{\circ} \mathrm{C}$ for about 48 hours to remove all the moisture.

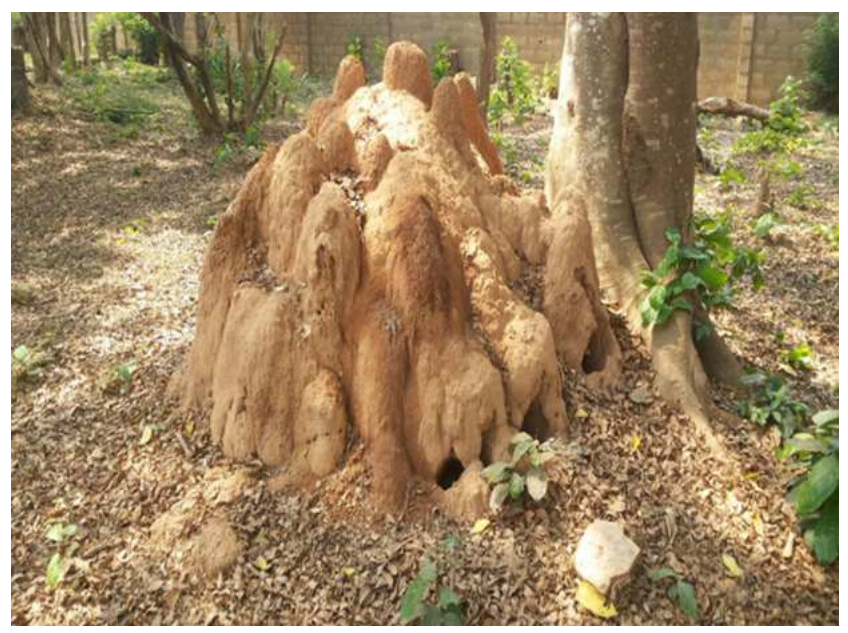

Figure 1. Termite mound clay, Ogunranti Village, Oyo State.

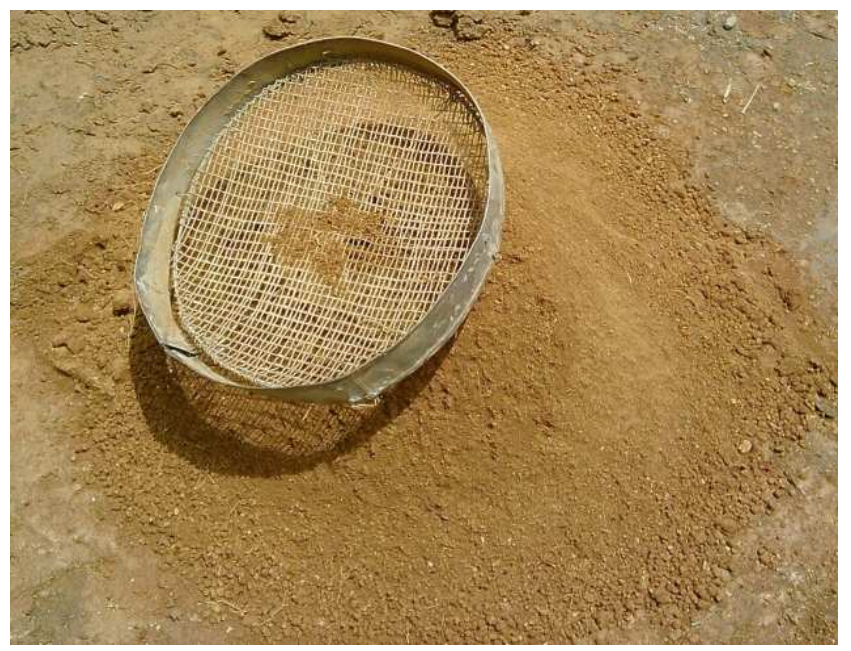

Figure 2. Sieved termite mound clay.

\subsection{Thermal Conductivity Determination}

The thermal conductivity was determined as described by [15] using a guarded hot-Figure apparatus with steady-state heat flow method as shown in Figure 3. The upper Figure was $90 \mathrm{~mm}$ in diameter and $30 \mathrm{~mm}$ thick and was surrounded by a guard ring of $120 \mathrm{~mm}$ in diameter and $13 \mathrm{~mm}$ thick. The gap between the Figure and ring was filled with fibre glass both at the top of the Figure and the sides to a thickness of $10 \mathrm{~mm}$. The lower Figure had a diameter of $90 \mathrm{~mm}$ and a 
thickness of $9 \mathrm{~mm}$. It was surrounded by a wooden guard ring of $125 \mathrm{~mm}$ in diameter and $14 \mathrm{~mm}$ thick, from which it was separated by fibre glass to a thickness of $14 \mathrm{~mm}$. The upper Figure was heated electrically and this was controlled using a variable voltage regulator connected with an ammeter.

Measurement of current and voltage were made using a multi-meter. The temperature of the Figure was measured with a $0.2 \mathrm{~mm}$ k-type thermocouple and a two-way digital thermometer at the heat source and heat sink respectively. The heat flux of the thermal conductivity apparatus was obtained by using polystyrene which is of known thermal conductivity and this was used to calibrate the apparatus. TMC samples were moulded in a cylindrical shaped mould of dimensions $7 \mathrm{~cm}$ diameter and $2.5 \mathrm{~cm}$ thickness. Thermal conductivity was computed from the temperature changes and heat flux obtained. The heat source was adjusted to maintain a temperature of approximately $150^{\circ} \mathrm{C}$. Temperature at the heat source and the heat sink was taken every minute until equilibrium was reached and the temperature difference was recorded and used in calculating the thermal conductivity of the sample from the equation below. The experiment was done using twenty replicates.

$$
\mathrm{k}=\mathrm{q}^{\prime} \mathrm{l} \Delta \mathrm{t}
$$

$\mathrm{k}=$ Thermal conductivity $(\mathrm{W} / \mathrm{m}-\mathrm{K})$

$\mathrm{q}^{\prime}=$ heat flux $\mathrm{Wm}^{-2}=\mathrm{q}($ in $W) * \mathrm{~A}\left(\right.$ in $\left.\mathrm{m}^{2}\right)$

$\mathrm{l}=$ thickness $(\mathrm{m})$

$\Delta \mathrm{t}=$ change in temperature

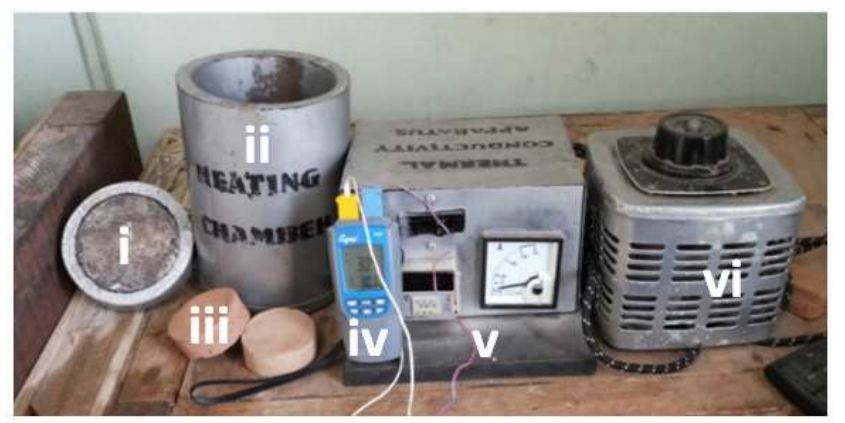

Figure 3. Guarded hot-Figure apparatus (where $i=H o t$ Figure, ii=Heating chamber, iii=Termite mound clay samples, $i v=$ Digital two-way thermometer, $v=$ Ammeter, $v i=$ Voltage regulator).

\subsection{Specific Heat Capacity}

A TMC specimen of known mass and temperature was placed into a calorimeter of known specific heat containing water of known temperature and mass. The mixture was stirred continuously using a copper stirrer and the temperature of the mixture was recorded at an interval of 60 seconds until an equilibrium temperature is reached using a K-type thermocouple digital thermometer. The specific heat of the sample was then computed from the heat balance equation between the heat gain or loss by water and calorimeter and the heat loss or gain by the sample in the system. Specific heat capacity was calculated using the heat balance equation as stated in equation 2 . The experimental setup is shown in Figure 4.

$$
C_{s}=\left[M_{c} C_{c}+M_{w} C_{w}\right]^{\times}\left[T_{w}-\left(T_{e}+t^{\prime} R^{\prime}\right)\right]^{\times} M_{s}\left(T_{e}+t^{\prime} R^{\prime}-T_{s}\right]
$$

Where;

$\mathrm{C}_{\mathrm{s}}=$ specific heat of sample $(\mathrm{J} /(\mathrm{kg} \cdot \mathrm{k}))$

$\mathrm{C}_{\mathrm{c}}=$ specific heat of calorimeter $(\mathrm{J} / \mathrm{kg} \cdot \mathrm{k})$

$\mathrm{C}_{\mathrm{w}}=$ specific heat of water $(\mathrm{J} / \mathrm{kg} \cdot \mathrm{k})$

$\mathrm{M}_{\mathrm{c}}=$ mass of calorimeter $(\mathrm{kg})$

$\mathrm{M}_{\mathrm{w}}=$ mass of water $(\mathrm{kg})$

$\mathrm{T}_{\mathrm{w}}=$ temperature of water $(\mathrm{K})$

$\mathrm{T}_{\mathrm{s}}=$ temperature of sample $(\mathrm{K})$

$\mathrm{T}_{\mathrm{e}}=$ equilibrum temperature $(\mathrm{K})$

$\mathrm{t}^{\prime}=$ time taken to reach equilibrum $(\mathrm{sec})$

$\mathrm{R}^{\prime}$ = rate of temperature drop of mixture after equilibrum $(\mathrm{K} / \mathrm{sec})$

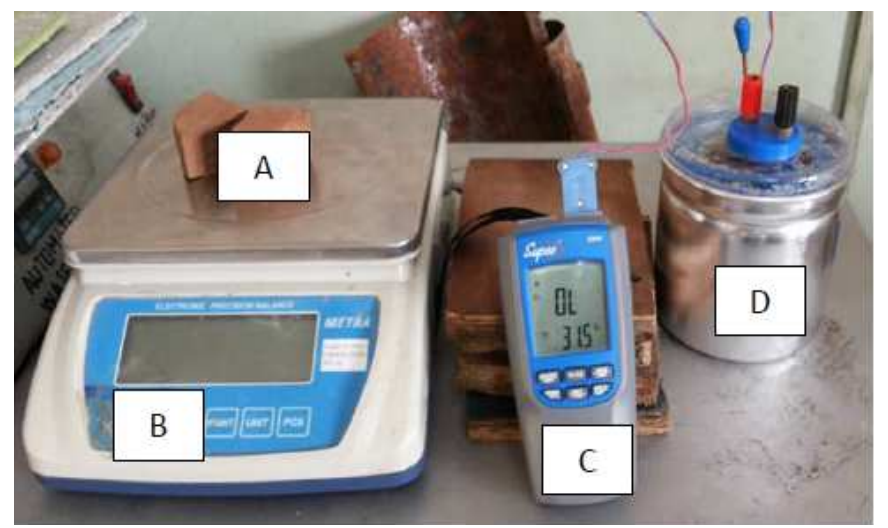

Figure 4. Specific Heat Capacity Determination (A=Termite mound clay samples, $B=$ Digital weighing balance, $C=$ Digital thermometer, $D=C o p p e r$ calorimeter).

\subsection{Thermal Diffusivity Determination}

The thermal diffusivity of both samples was determined by using the experimental values of thermal conductivity, specific heat capacity and the density of the samples. The formula relating all these properties is stated in equation 3 .

$$
\alpha=\mathrm{K} \times \rho \times \mathrm{Cs}
$$

$$
\begin{aligned}
& \alpha=\text { thermal diffusivity of the sample }\left(\mathrm{m}^{2} / \mathrm{sec}\right) \\
& \mathrm{K}=\text { thermal conductivity }(\mathrm{W} / \mathrm{mK}) \\
& \rho=\text { density }\left(\mathrm{kg} / \mathrm{m}^{3}\right) \\
& \mathrm{Cs}=\text { specific heat capacity }(\mathrm{KJ} / \mathrm{kgK})
\end{aligned}
$$

\subsection{Thermal Mass Determination}

The thermal mass of both samples was determined by using the experimental values of density and specific heat capacity of the samples using equation 4 :

$$
\mathrm{Cth}=\rho \times \mathrm{Cs}
$$

$\mathrm{C}_{\mathrm{th}}=$ thermal mass of the sample $\left(\mathrm{J} / \mathrm{m}^{3} \cdot \mathrm{k}\right)$

$\rho=$ density $\left(\mathrm{kg} / \mathrm{m}^{3}\right.$, density was calculated from the ratio of mass/volume at oven dry state)

$\mathrm{C}_{\mathrm{s}}=\operatorname{specific}$ heat capacity $(\mathrm{J} /(\mathrm{kg} \cdot \mathrm{k}))$ 


\section{Results and Discussion}

The results are presented and discussed below:

\subsection{Thermal Conductivity}

The results obtained from the experiment showed that thermal conductivity values ranged from 0.17 to $0.24 \mathrm{~W} / \mathrm{m} \cdot \mathrm{k}$ with a mean value of $0.21 \mathrm{~W} / \mathrm{m} \cdot \mathrm{k}$. Thermal conductivity of clay at $0 \%$ moisture content is reported to be about 0.25 $\mathrm{W} / \mathrm{m} \cdot \mathrm{k}[16,17]$. This is similar to what was obtained for TMC thus confirming that it is a good insulator which can inhibit heat transfer into stored grains, a very important factor in postharvest grain management. Thus, TMC has an advantage over other materials of construction for grain storage in terms of heat transfer such as concrete which ranges between $0.8-1.28 \mathrm{~W} / \mathrm{m} \cdot \mathrm{k}$ and stainless steel of about $16.3-16.7 \mathrm{~W} / \mathrm{m} \cdot \mathrm{k}$ (obtained from Wikipedia [18]) as shown in Figure 5.

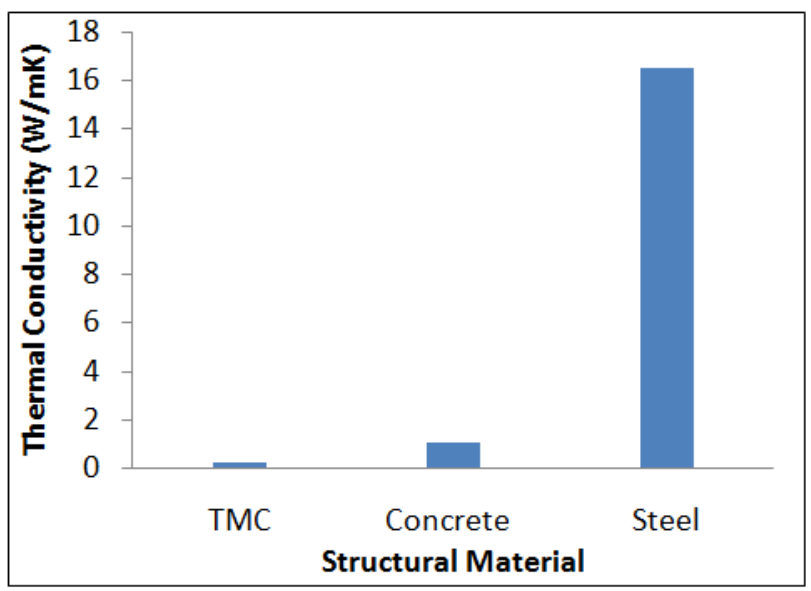

Figure 5. Comparison between Thermal Conductivity of TMC, Concrete and Steel.

\subsection{Specific Heat Capacity}

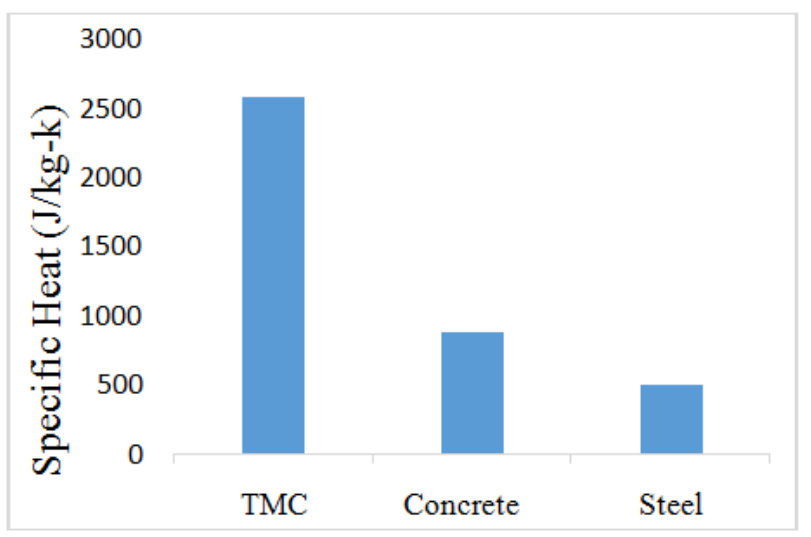

Figure 6. Comparison between the Specific Heat of TMC, Concrete and Steel.

The values of specific heat capacities of TMC obtained ranged from $2142.7-2965.7 \mathrm{~J} / \mathrm{kg} \cdot \mathrm{K}$ with an average value of $2576.9 \mathrm{~J} / \mathrm{kg} \cdot \mathrm{K}$ and this was found to be higher than those of concrete and steel which had values of 960 and $490 \mathrm{~J} / \mathrm{kg} \cdot \mathrm{K}$ respectively (obtained from the Engineering-Toolbox [19]) as shown in Figure 6. This means the amount of heat required to raise the temperature of a unit weight of TMC will be more when compared to that of steel and concrete. This is also an advantage if TMC is used in silo construction since incidences of temperature fluctuations within the silo will be minimized.

\subsection{Thermal Diffusivity}

The thermal diffusivity of TMC ranged from $1.31 \times 10^{-8}$ $1.75 \times 10^{-8} \mathrm{~m}^{2} / \mathrm{s}$ with an average value of $1.47 \times 10^{-8} \mathrm{~m}^{2} / \mathrm{s}$ compared to that of concrete and steel whose calculated values $\left(6.63 \times 10^{-7}\right.$ and $\left.4.18 \times 10^{-6}\right)$ are shown in the Table 3.1. The lower value of thermal diffusivity in TMC indicates that it is a better insulating material because movement of thermal energy through TMC will occur at a slower rate than in other materials as shown in Figure 7 indicates that. This implies that the tendency for increased grain temperature in a TMC silo is minimized when compared to grains stored in either concrete or steel bins, an advantage in grain storage.

Table 3.1. Thermal diffusivity of concrete and steel.

\begin{tabular}{lllll}
\hline Material & $\begin{array}{l}\text { Mean } \\
\text { Density } \\
\left(\mathbf{k g} / \mathbf{m}^{\mathbf{3}}\right)\end{array}$ & $\begin{array}{l}\text { Thermal } \\
\text { conductivity } \\
\mathbf{( W / m} \cdot \mathbf{k})\end{array}$ & $\begin{array}{l}\text { Specific heat } \\
\text { capacity } \\
(\mathbf{J} / \mathbf{k g}-\mathbf{k})\end{array}$ & $\begin{array}{l}\text { Thermal } \\
\text { diffusivity } \\
\left(\mathbf{m}^{\mathbf{2}} \mathbf{s}^{\mathbf{1}}\right)\end{array}$ \\
\hline Concrete & 2400 & 1.4 & 880 & $6.63 \times 10^{-7}$ \\
Steel & 7820 & 16 & 490 & $4.18 \times 10^{-6}$ \\
\hline
\end{tabular}

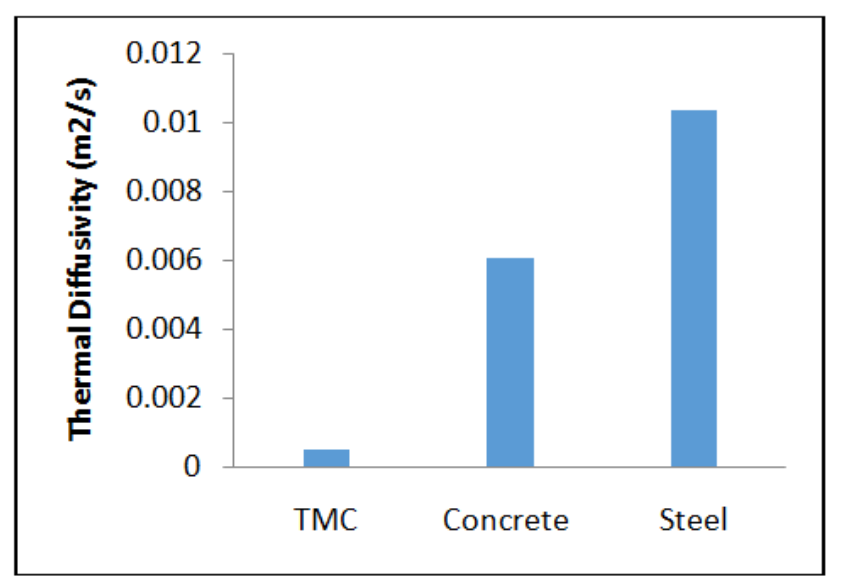

Figure 7. Comparison between the Thermal Diffusivity of TMC, Concrete and Steel.

\subsection{Thermal Mass}

The thermal mass of TMC ranged from 3927.6- 5436.1 $\mathrm{kJ} /\left(\mathrm{m}^{3} \cdot \mathrm{K}\right)$ with a mean value of $4723.5 \mathrm{~kJ} /\left(\mathrm{m}^{3} \cdot \mathrm{K}\right)$. Thermal mass for concrete and steel were calculated from values shown in Table 3.2. TMC has higher thermal mass when compared to concrete and steel as shown in Figure 8. The implication of this is that TMC has the tendency to act as a heat sink, storing heat energy during hot periods which can later be released either to the stored grains or the surrounding environment during cool periods. Depending on the direction 
of heat flow, this might be a disadvantage in the humid tropics when long term grain storage is to be considered, most especially if direction of heat flow is into the stored grains as it better to have cool grains rather than warm.

Table 3.2. Thermal Mass of Concrete and Steel.

\begin{tabular}{llll}
\hline Materials & Density $\mathbf{k g} / \mathbf{m}^{\mathbf{3}}$ & $\begin{array}{l}\text { Specific heat } \\
\text { capacity }(\mathrm{kJ} / \mathbf{k g} \cdot \mathbf{K})\end{array}$ & $\begin{array}{l}\text { Thermal mass } \\
\left(\mathbf{k J} / \mathbf{m}^{\mathbf{3}} \cdot \mathbf{K}\right)\end{array}$ \\
Concrete & 2400 & 0.88 & 2112.0 \\
Steel & 7820 & 0.49 & 3831.8 \\
\hline
\end{tabular}

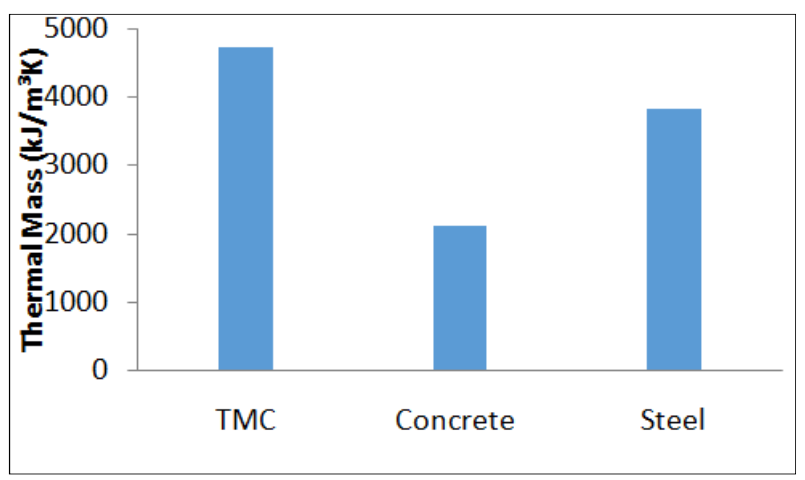

Figure 8. Comparison between the Thermal Mass of TMC, concrete and steel.

\section{Conclusion and Recommendations}

The thermal properties of termite mound clay were investigated as a potential material of construction for grain storage silos in comparison with concrete and steel which are common materials used in grain silo construction. It was concluded that from a thermal point of view, termite mound clay compares well and exhibits better heat insulating properties. However, in relation to its thermal mass property, further studies should be conducted on TMC to ascertain the likely direction of heat flow during cool periods.

\section{References}

[1] Y. Mijinyawa (2010): "Farm Structures"; University of Ibadan Publishing House (ISBN: 978 - $978-8414-35-3$ ).

[2] C. Karthikeyen, D. Veeraragavathatham, D. Karpagam and S. Ayisha Firdouse (2009): Indigenous storage structures. Division of Agricultural Extension, Krishi Vigyan Kendra, Sirugamani 639 115, Tiruchirappalli, Tamil Nadu. Indian Journal of Traditional Knowledge Vol. 8(2), April 2009, pp. 225-229.

[3] Y. Mijinyawa, E.B. Lucas and F.O. Adegunloye (2007): Termite Mound Clay as Material for Grain Silo Construction, Agricultural Engineering International: the CIGREjournal. Manuscript BC 07002 Vol IX July 2007; http://cigrejournal.tamu.edu/submissions/volume9/BC\%2007\%20002\% 20Mijinyawa\%20final\%2024July2007.pdf

[4] J.T. Mills (1989): Spoilage and heating of stored agricultural products: prevention, detection and control. (Publication: 1823E) Includes Index. Bibliography: SB129.M54 1988 631.5'68 C88099204-2.
[5] C.M. Geoffrey, L.O. Gumbe, H.J. Chepete and J.O. Agullo (2011): Rural structures in the tropics. Design and development. CTA Postbus 380, 6700 AJWageningen, The Netherlands; www.cta.int.

[6] HGCA-Agriculture and Horticulture Development Board (2011): Grain storage guide for cereals and oilseeds. Third edition; www.hgca.com

[7] B.A. Alabadan (2006): Evaluation of Wooden Silo during Storage of Maize (Zea mays) in Humid Tropical Climate; Agricultural Engineering International; the CIGR Ejournal, Manuscript BC 05 013, Vol VIII.

[8] A.C. Yunus (2002): Heat Transfer: A Practical Approach second edition. Publisher: Mcgraw-Hill companies. ISBN-10: 0072458933 ISBN-13: 978-0072458930.

[9] G. Ayugi, E.J. Banda, F.M. D’Ujanga (2011): Local Thermal Insulating Materials for Thermal Energy Storage. Department of Physics, Makerere University, P.O. Box 7062 Kampala, Uganda, email: agertrude@physics.mak.ac.ug. Tel. +256782 232 742. Rwanda Journal, Volume 23 Series C, 2011: Mathematical Sciences, Engineering and Technology.

[10] M.A. Oladunjoye and O.A. Sanuade (2012): Thermal diffusivity, thermal effusivity and specific heat of soils in OlorunsogoPowerplant, Southwestern Nigeria. Department of Geology, University of Ibadan.

[11] D. Salmon, G. Roebben, A. Lamberty, R. Brandt (2007): Certification of thermal conductivity and thermal diffusivity up to $1025 \mathrm{~K}$ of a glass-ceramic reference material BCR-724. European Commission, Directorate-General Joint Research Centre Institute for Reference Materials and Measurements.

[12] D. Baggs. and N. Mortensen (2006): Thermal Mass in Building Design. The BDP Environment Design Guide is published by The Royal Australian Institute of Architects.

[13] W. Rory., P. Kenny and V. Brophy (2006): Thermal Mass and Sustainable Building, Improving Energy and Occupant Comfort. UCD Energy Research Group, University College Dublin.

[14] Y. Mijinyawa and M.O. Omobowale (2013): Determination of Some Physical and Mechanical Properties of Termite Mound Clay Relevant to Silo Construction; International Journal of Materials Engineering, Vol. 3 No. 5; pp. 103-107.

[15] A.K. Aremu and H.U. Nwannewuihe (2011): Specific Heat of Ground Fresh Sheanut Kernel (Butyrospernumparadoxum) as Affected by Particle Size, Moisture Content and Temperature. Journal of Emerging Trends in Engineering and Applied Sciences (JETEAS) 2 (1): 177-183 C Scholarlink Research Institute Journals, 2011 (ISSN: 2141-7016) jeteas.scholarlinkresearch.org.

[16] J. Folaranmi (2009): Effect of Additives of the Thermal Conductivity of Clay; Leonardo Journal of Sciences, Issue 14, pp. $74-77$.

[17] D.R. Cook (2012): "Thermal Conductivity of Clay"; http://www.newton.dep.anl.gov/askasci/env99/env140.htm; Date Accessed: 10/07/2012.

[18] Wikipedia (2015): List of Thermal Conductivities; http://en.wikipedia.org/wiki/List_of thermal_conductivities; Date Accessed: 17/02/2015. 
[19] The Engineering Toolbox (2015b): 'Solids-Specific Heats'- A Comprehensive List of some common Materials and their
Specific Heats; http://www.engineeringtoolbox.com/specificheat-solids-d_154.html; Date Accessed: 19/02/2015. 